\title{
Fungsi Dan Manfaat Cabang-Cabang Hadis Dalam Perspektif Studi Hadis
}

\author{
Kaharuddin \& Anwar Sadat \\ Insitut Agama Islam (IAI) Muhammadiyah Bima
}

\begin{abstract}
Abstrak. Islam merupakan sistem nilai dan ajaran illahiyah yang bersifat transendental. sehubungan dengan hal itu, ajaran Islam sebagai sesuatu sistim universal akan selalu hadir dinamis dan selalu mampu menjawab berbagai tantangan zaman. Kondisi tersebut didasarkan pada keberadaan sumber ajaran Islam yang kokoh, yaitu Al-Qur'an, dan Hadist. Al-Qur'an adalah firman Allah SWT yang di dalamnya terkandung ajaran pokok untuk keperluan seluruh aspek kehidupan. Sedangkan Hadist/Sunnah merupakan segalah sesuatu yang disandarkan kepada Nabi Muhammad SAW yang berisi petunjuk (pedoman) untuk kemaslahatan hidup umat manusia. Namun berbeda dengaan Al-Qur'an, perkembangan Hadist/Sunnah tidak semulus Al-Qur'an. Berbagai keraguan bahkan penolakan muncul seiring pertumbuhan studi terhadap Hadist/Sunnah itu sendiri. Keraguan terhadap hadits, lebih memuncak ketika munculnya masyarakat yang menganggap bahwa hadis memiliki tingkatan yang sama diantaranya; masyarakat awam yang cenderung memberikan anggpan terhdapa hadis itu sama tidak membedakan membedakan hadis shohih dan hadis yang dho'if, hasan, dll sehingga menyimpang tentang kemurnian hadis Nabi. Bahkan pada sisi yang lain, muncul pula pandangan para tokoh orientalis yang menganggap hadis sebagai sumber terpercaya awal masa Islam, melainkan hanya sebagai sumber dogma, konflik serta perhatian muslim belakangan yang telah menyebarkan hadis.
\end{abstract}

\section{Kata Kunci. Fungsi dan manfaat cabang-cabang Hadis}

\section{PENDAHULUAN}

Islam sebagai agama samawi memiliki sumber ajaran, yaitu al-Qur'an dan Nabi Muhammad saw sebagai pembawa risalah diberikan kewenangan oleh Allah swt untuk menjelaskan kepada umatnya tentang wahyu yang diterimanya, dan penjelasan Nabi tersebut dikenal dengan istilah hadis Nabi atau sunah.

Sebagian besar kaum muslimin meyakini bahwa hadis adalah kendaraan sunah Nabi dan bahwa hadis merupakan tuntunan yang tidak dapat diabaikan dalam memahami wahyu Allah swt. Sebagai salah satu sumber otoritas Islam kedua setelah alQur'an, sejumlah literatur hadis memiliki pengaruh yang sangat menetukan serta menjadi sumber hukum dan inspirasi agama. Para ulama telah berupaya keras mengumpulkan dan mengklasifikasi serta memilah hadis yang autentik dan yang palsu. Di satu sisi, para sarjana muslim belajar hadis lebih didorong oleh peran sentral yang dimainkan oleh hadis sebagai sumber hukum dan doktrin teologis, sedangkan serjana barat mempelajari hadis pada dasarnya didorong oleh kepentingan sejarah (historis interest).
Dalam pendekatan historiografi, pertumbuhan hadis telah terjadi pada masa Rasulullah saw, selanjutnya dikembangkan oleh para sahabat, tabi'in samapai dapat dikumpulkan menjadi sebuah kitab. Hadis tidak seperti al-Qur'an yang dikumpulkan dalam sebuah mushaf, hadis dikumpulkan oleh banyak penulis berdasarkan hafalan dan pengetahuanya. Oleh sebab itu, hadis-hadis Nabi Muhammad saw terkumpul beberapa kitab yang disusun oleh masing masing mukharrij atau penulis.

Proses perkembangan hadis barlangsung dari satu generasi kegenerasi berikutnya. Hadis berkembang dalam kurun waktu bertahun-tahun dan berabad yang lalu, sehingga muncul keraguan dan kecurigaan pada riwayat tertentu atau orang tertentu. Mulai abad ke-19, pertanyaan tentang autensitas, originalitas, asal muasal, keakuratan serta kebenaran hadis, muncul dan menjadi isu pokok dalam srtudi Islam. Pertanyaan ini muncul dari para sarjana Barat dan juga sarjana Muslim. Abu rayyah misalanya, berpendapat bahwa hadis Nabi telah rusak dan kata-kata persisya telah hilang karena riwayah bi al-ma'na (periwayatan 
secara makna, bukan hafal). Gustav Weil menyarankan sarjana barat untuk menolak paling tidak separuh hadis yang terdapat dalam Shahih Al-Bukhari. Selain itu, ada juga sarjana barat seperti, Alois Sprenger yang menyatakan keragu-raguanya terhadap kepercayaan (Tsiqah) hadis sebagai sumber sejarah.

Kesarjanaan hadis eropa mencapai puncak dalam karya Ignaz Goldziher, dan menjadi karya krtik hadis terpenting pada abad ke-19. Ia tidak menganggap hadis sebagai sumber terpercaya awal masa Islam, melainkan hanya sebagai sumber yang sangat bernilai sebagai dogma, konflik serta perhatian muslim belakangan yang telah menyebarkan hadis.

Terlepas dari konsepsi yang dikemukakan oleh para sarjana barat, yang umumnya menolak hadis sebagai sumber ajaran umat Islam, dan menjustifikasi bahwa hadis diragukan originalitasnya dari segi perkembangan hadis sebagai sumber hukum. Tetapi sebagai generasi muslim yang baik, kita tidak harus terjebak dalam peryataan tersebut, melainkan berupaya untuk mempelajari perkembangan hadis dengan sungguh-sungguh dalam bentuk pendekatan keilmuan Islam.

Lebih tegas lagi, penulis menganggap bahwa asumsi yang dibangun oleh para orientalis itu, merupakan cara pandang yang subyektif karena parameter mereka dalam mengukur hadis hanya dari pendekatan sejarah, tidak memahami hadis secara komprehensif sebagi sumber ajaran agama Islam.

Berangkat dari fakta tersebut, maka diperlukan sebuah kaidah atau kriteria penerimaan riwayat, atau syarat-syarat seseorang yang dapat diterima riwayatnya. Kaidah atau kriteria yang dimaksud adalah metode untuk mengetahui apakah hadis tersebut sahih atau da'if, dan salah satu pendekatan yang mesti dipelajari yakni memahami perkembangan ilmu hadis (Ulum al-Hadith), karena pemahaman yang cukup tentang ilmu hadis maupun cabang-cabangnya dapat menguatkan paradigma secara obyektif bahwa hadis sebagai sumber ajaran dan hukum Islam sangatlah penting bagi kehidupan sehari-hari.

Atas dasar itulah, dalam kesempatan ini penulis akan menguraikan secara sederhana sebuah makalah seputar ilmu hadis (Ulum al-hadith), dengan muatan pembahasan, antara lain: pengertian ilmu hadis, cabang-cabang ilmu hadis, serta manfaat ilmu hadis.

Besar harapan penulis, pembahasan makalah ini dapat memberikan sumbangsi pengetahuan, terkhusus bagi penulis dan insan-insan yang sangat peduli akan pentingnya kedudukan hadis tertuma yang berkaitan dengan ilmu hadis (ulum al-hadith).

\section{Ilmu Hadis}

Hadis merupakan pedoman hidup yang harus diikuti dan diimplementasikan dalam kehidupan sehar-hari. Melihat kedudukan hadis yang sangat penting itu, maka setiap umat Islam harus mempelajari hadis dan limu-ilmunya, agar dapat mengetahui dan memahami hal ihwal hadis secara maksimal untuk pengamalan syari'at Islam, serta untuk melakukan istimbath hukum agar dapat mengetahui problematikanya, sehingga dapat meletakan hadis pada proporsi yang sebenarnya.

Berangkat dari maksud di atas, ada beberapa hal yang perlu dicermati dan dipelajari secara seksama terkait tentang pentingnya ilmu hadis, antara lian:

\section{Definisi ilmu hadis}

Dari segi bahasa kata Ilmu Hadis berasal dari bahasa arab, yaitu 'ilm dan hadits. Kata 'ilm berarti "pengetahuan", sedangkan kata hadits berati "yang baru, pembicaraan, berita dan ceritra." Pada penjelsan sebelumya, hadis didefinisikan sebagai segala sesuatu yang disandarkan pada Nabi Muhammad saw, baik berupa perkataan, perbuatan, taqrir, maupun hal ihwalnya (sifat-sifatnya).

Dengan demikian ilmu hadis dapat diartikan sebagai sebuah ilmu pengetahuan yang membicarakan tentang cara-cara persambungan hadis sampai kepada Rasulullah saw, dari segi ihwal para perawinya, kedabitan, keadilan, dan dari bersambung tidaknya sanad dan sebagainya.

Lebih terperinci lagi, bila merujuk definisi ilmu hadis menurut para ulama, 
seperti yang dikemukakan oleh Ibnu Hajar alAsqalaniy dalam kitabnya Tadrib al- Rawiy, yang menuturkan bahwa, ilmu hadis ialah pengetahuan tentang kaidah-kaidah yang dijadikan jalan untuk menegtahui keadaan perawi dan yang diriwayatkanaya. Selanjutnya, menurut Ibn al-Akfani dalam kitab tulisanya Irsyadul Qashid, mendefinisikan ilmu hadis adalah sesuatu ilmu yang dengan dia dapat diketahui macammacam riwayat, hukum-hukumya, syaratsyarat para perawi, sifat-sifat yang diriwayatkan dan cara-cara memahami maknanya. Senada dengan pendapat kedua ulama sebelumnya, para ulama mutaakhirin mengatakan ilmu hadis adalah sutau ilmu yang denganya diketahui keadaan perawi dan diriwayakan dari segi deterima dan ditolaknya.

Dari uraian tentang definisi ilmu hadis dapat dipahami oleh penulis bahwa ilmu hadis merupakan suatu pendekatan pengetahuan yang untuk mempelajari muatan-muatan hadis secara sunbstansi, agar dapat memilah, menilai dan menetapkan hadis berdasarkan nilai keakuratan dalam proses periwayatannya.

\section{Perbedaan pandangan ulama}

Menyangkut persoalan ilmu hadis, para ulama berbeda pandangan dalam memberikan nama ilmu hadis. Ada yang memberi nama 'Ulum al-Hadis; ada yang memberi nama 'Ilm Ushul al-Hadist; ada yang memberi nama'Ilm Mushthalah alHadits; ada juga yang memberi nama'Ilm Mushthalah Ahl al-Atsar; selain itu, ada pula sebagian ulama memberi nama ilmu hadis dengan sebutan Metode Kritik Hadis; maupun Metode Kajian Hadis.

Meskipun nama-nama ilmu hadis yang dikemukakan oleh para ulama itu berbeda, akan tetapi yang dimaksud adalah sama, yang berbeda hanya cakupan pembahasannya yang bisa tidak sama. Keseluruhan, ilmu tersebut membahas tentang ilmu hadis Nabi Muhammad saw.

\section{Perkembangan ilmu hadis}

Dalam perkembangan selanjutnya, para ulama hadis mengklasifikasi ilmu hadis menjadi dua bagian, antara lain:

\section{Ilmu hadis riwayah}

Yang dimaksud dengan ilmu hadis riwayah ialah ilmu pengetahuan yang mempelajari hadsi-hadis yang disandarkan kepada Nabi saw, baik berupa perkataan, perbuatan, taqrir maupun tingkah lakunya.

Menegaskan uraian di atas, menurut Ibn al-Akfani sebagai mana yang dikutib oleh Al-Suyuthi, mengatakan bahwa "ilmu Hadis Riwayah ialah ilmu pengetahuan yang mencakup perkataan dan perbuatan Nabi saw., baik periwayatanya, pemeliharaanya, maupun penulisan dan pembukuan lafazlafaznya". Dengan kata lain ilmu hadis riwayah adalah ilmu tentang matan hadis.

Pokok pembahasan ilmu hadis riwayah berkisar tentang proses periwayatan kepada orang lain, pencatatan, dan pengkajian sanad-sanadnya, serta menguji status setiap hadis; apakah sahih atau da'if. Adapun faedah dalam mempelajari ilmu hadis riwayah, yaitu untuk menjaga As-sunah dan menghindari kesalahan dalam periwayatan.

\section{Ilmu hadis dirayah}

Yang dimaksud dengan limu hadis dirayah ialah ilmu yang mempunyai beberapa kaidah (patokan), yang dengan kaidah-kaidah itu dapat diketahui keadaan perawi (sanad) dan yang diriwayatkan (merawiy) dari segi diterima atau ditolaknya.

Ada beberapa ulama yang memberi definisi ilmu hadis dirayah, di antaranya; Menurut Ibn al-Akfani mendefinisikan, bahwa ilmu dirayah ialah ilmu pengetahuan untuk mengetahui hakikat periwayatan, syarat-syarat, macam-macam, dan hukumhukumnya ,serta untuk mengetahui keadaan para perawi, baik syarat-syaratnya, serta macam macam hadis yang diriwayatkan dan segala yang berkaitan denganya. Sebagian ulama yang lainnya, seperti; Izs al-Din Ibn Jama'ah menjelaskan bahawa ilmu dirayah, ialah ilmu pengetahuan tentang kaidah-kaidah yang denganya diketahui keadaan sanad dan matan.

Dari beberapa pengertian di atas, dapat diketahui bahwa pokok pembahasan ilmu hadis dirayah adalah keadaan perawi dan merawinya. Keadaan para perawi, baik yan menyangkut pribadinya, seperti akhlak, tabi'at, dan keadan hafalannya, maupun yang 
menyangkut persambungan dan terputusnya sanad.

Adaupun faedah ketika dalam mepelajari ilmu hadis dirayah, yaitu untuk mengetahui kualitas sebuah hadis, apakah hadis tersebit diterima dan ditolak, baik dari sudut sanad maupun matanya.

\section{Cabang-Cabang Ilmu Hadis}

Dari ilmu hadis riwayah dan hadis dirayah, pada perkembangan berikutnya, muncullah cabang-cabang ilmu hadis lainya. Dan cabang-cabang ilmu hadis tersebut digolongkan dalam beberapa kategori, sebagai berikut:

Cabang ilmu hadis yang pokok bahasanya menekankan pada persoalan sanad dan rawi, terdiri atas:

a. Ilmu rijal al-hadis

Ilmu yang membahas secara umum tentang hal ihwal kehidupan para perawi, baik dari golongan sahabat, tabi'in, maupun angkatan sesudahanya. Ilmu rijal al-hadits dinamakan juga ilmu tarik al-ruwah, ialah ilmu untuk mengetahui keadaan para perawi hadis.

Ilmu ini sangat penting kedudukanya dalam lapangan ilmu hadis. Karena ilmu in lahir bersama-sama dengan periwayatan hadis dalam islam dan mengambil porsi khusus yang mempelajari persoalan-persoalan disekitar sanad. Di antara kitab yang paing tua tentang sejarah perawi terdapat pada kitab Thabaqat Al-Kubra karya Muhammad Ibn Sa'ad (w. $230 \mathrm{H}$ ). Ilmu tabaqat al-ruwah

Ilmu yang membahas tentang keadaan perawi berdasarkan pengelompokan dalam keadaan tertentu. Umpamanya dari segi pengelompokan dari segi umurnya, dari segi gurunya dan sebagainya. Atau dalam makna sederhannya, ilmu ini menekankan pada pemetaan para perawi hadis dari segi umur, dan kepada siapa dia berguru.

b. Ilmu tarikh rijal al-hadis

Ilmu yang membahas tentang keadaan perawi hadis dari segi data kelahiranya, silsila keturunannya, gurunya dan muridnya, bahkan sampai pada jumlah hadis yang diriwayatkan dan murid-murid yang pernah berguru padanya. ${ }^{1}$ Dengan ilmu ini, dapat diketahui keadaan perawi hadis seperti kelahiranya, wafatnya, guru-gurunya, orang yang meriwatkan darinya, negeri dan tanah air mereka, atau yang berhubugan dengan sejarah para perawi.

c. Ilmu jahri wa al-ta'dil

Ilmu yang membahas tentang para perawi hadis, dari segi yang dapat menunjukan keadaan mereka, baik mecacatkan atau membersihkan mereka, dengan ungkapan atau lafal tertentu. Sehingga dapat ditentukan siapa diantara perawi yang dapat diterima atau ditolak sebuah riwayatnya.

Ada beberapa tokoh sahabat yang sering membicarakan persoalan perawai dan sekaligus memplopori ilmu jarh wa al ta-dil, mereka adalah: Anas bin Malik, Ubadah bin Ash-Shamit dan Abdullah bin Abbas.

\section{Cabang ilmu hadis yang pokok pembahasanya menekankan pada persoalan matan hadis, terdiri atas:}

a. Ilmu gharib al-hadis

Ilmu yang menerangkan tentang lafazh-lafazh yang sulit dipahami dalam matan hadis, karena lafazh tersebut jarang sekali digunakan, karena terkandung nilai sastra yang sangat tinggi.

Ilmu ini muncul atas inisiatif para ulama untuk memudahkan dalam memahami hadis-hadis yang mengndung lafazh-lafazh gharib tersebut. Karena memahami kosa kata (mufrad) matan hadis merupakan langkah pertama dalam memahmi suatu hadis serta untuk melakuakn istinbath hukum.

Sejak dimulainya pembukuan hadis pada ahir abad kedua dan awa abad hijriyah, para ulama sudah menyusun buku tantang gharib al-hadis. Dan tokoh ulama yang pertama kali menyusun gharib al-hadis adalah Abu Ubaidah Mu'amar bin al-Mutsana AtTaini (wafat $210 \mathrm{H}$ ).

b. Ilmu asbab wurud al-hadis

Ilmu yang membahas tentang sebabsebab atau latar belakang lahirnya sebuah hadis. Ilmu ini sangat penting mengantar untuk memahami hadis tentang kondisi yang

\footnotetext{
${ }^{1}$ Ambo Ase, Ilmu Hadis Pengantar Memahami Hadis Nabi Saw, h. 135.
} 
dihadapi dan menjadi sebab hadis itu diucapkan.

Menguatkan maksud di atas, menurut Prof Dr. Zuhri ilmu asbab wurud al-hadits adalah ilmu yang menyingkapi sebab-sebab timbulnya hadits. Terkadang, ada hadits yang apabila tidak diketahui sebab turunnya, akan menimbulkan dampak yang tidak baik ketika hendak diamalkan. Ulama yang merintis ilmu ini adalah Abu Hamid bin Kaznah al-Jubary dan Abu Hafsh Umaru bin Muhammad bin Raja al-Ukbari.

c. Ilmu tawarikh al-mutun

Ilmu yang menerangkan tantang kapan sebauah hadis itu diucapkan atau diperbuat oleh Rasulullah saw, yang dilihat dari aspek ( tempat, waktu, dan kondisi). Imu ini sangat penting dan berguna untuk mengantar dalam memahami sebuah hadis dar statusya, atau apakah hadis tersebut terjadi nasikh mansukh. Ulama yang merintis ilmu ini adalah, Sirajuddin Abu Hafsh Amr al-Bulkiny.

d. Ilmu al-nasikh wa al-mansukh

Ilmu yang membahas hadis-hadis yang yang berlawanan yang tidak mungkin untuk dipertemukan karena materinya (berlawanan) yang pada akhirnya terjadilah saling menghapus, dengan ketetapan yang datang terdahulu disebut mansukh dan yang datang kemudian dinamakan naskh.

e. Ilmu talfiq al- hadis

Ilmu yang menerangkan tentang cara/metode mengumpulkan hadis-hadis yang saling bertentangan atau berlawanan. Cara untuk mengumpulkan atau mengkompromikan hadis yang beralawanan tersebut. Ulama yang pertamamenulis ilmu ini adalah Imam Safi'i dengan kitabnya "mukhtalif al-hadis".

f. Ilmu tashhif wa al-tahrif

Ilmu yang menerangkan tentang hadis-hadis yang sudah diubah titik dan syakalnya dan bentiknya. Atau dalam makna lainya, ialah ilmu yang menjelaskan terjadi perubahan lafazh dan tanda bacanya dalam hadis. Dan ulam yang dianggap sebagai perintis dari ilmu ini ialah: Imam alDaruquthny (w. $358 \mathrm{H}$ ) dan Abu Ahmad asAskary (w. $283 \mathrm{H}$ ).

\section{Cabang ilmu hadis yang pokok pembahasanya menekankan pada}

\section{persoalan sanad dan matan, terdiri atas:}

a. Ilmu i'ilal al hadis

Ilmu yang menerangkan tantang sebab yang dapat mencacatkan hadis. Ulama yang dipandang ahli dalam ilmu ini, di antaranya: Ibnu Al-Madny, Ahmad bin Hanbal, alBukhari.

b. Ilmu al-fanni al-mubhamat

Ilmu yang menerangkan tentang nama-nama orang yang tidak disebutkan dalam sanad hadis. Ulam yang merintis ilmu ini adalah al-Khatib al-Bagdady.

\section{Manfaat Mempejari Cabang-Cabang Ilmu Hadis}

Dalam mempelajari cabang-cabang ilmu hadis, ada beberapa manfaat utama yang dapat dipahami dan dicermati, antara lain:

1. Memberikan gambaran tentang cara untuk menjaga As-sunah dan menghindari kesalahan dalam periwayatannya.

2. Memberikan pengetahuan baru tentang cara mengetahui kualitas sebuah hadis, apakah hadis tersebut diterima dan ditolak, baik dari sudut sanad maupun matanya.

Meski demikian ada pula, manfaat lainnya secar spesifik ktika mempejarai cabang-cabang ilmu hadis, seperti:

1. untuk mengetahui pertumbuhan dan perkembagan hadis maupn ilmu hadis, dari masa ke masa sejak masa Rasulullah saw, sampai sekarang;

2. dapat mengetahu para tokoh-tokoh serta usaha yang telah mereka lakukan dalam mengumpulkan memelihara dan meriwayatkan hadis;

3. dapat mengetahui kaidah-kaidah yang dipergunakan oleh para ulama dalam mengklasifikasi hadis;

4. dapat mengetahui istilah-istialah, nilainilai dan kriteria-kriteria hadis sebagai pedoam dalam beristinbat.

Dengan uarain di atas, hemat penulis bahwa untuk memahami hadis dengan segala persoalannya, minimal kita sebagai generasi muslim harus mampu dan berusaha untuk megetahui tentang ilmu hadis, serta segala bentuk cabang-cabangnya, agar penerapan kehidupan di tengah-tengah masyarakat yang akan datang, kita bisa menjadi tameng dalam 
menyelasaikan setiap masalah-masalah yang muncul, tertama yang berkenaan dengan fiqih dan sebagainya.

\section{KESIMPULAN}

Berangkat dari beberapa masalah pokok yang menjadi pembahasan dalam ilmu hadis, penulis merumuskan beberapa kesimpulan:

1. Ilmu hadis dapat diartikan sebagai sebuah ilmu pengetahuan yang membicarakan tentang cara-cara persambungan hadis sampai kepada Rasulullah saw, dari segi ihwal para perawinya, kedabitan, keadilan, dan dari bersambung tidaknya sanad dan sebagainya.

2. Cabang-cabang ilmu hadis dapat diaktegorikan ke dalam tiga bagian, antara lain:

a. ilmu hadis yang menekankan pada persoalan sanad dan rawi, seperti: Ilmu Rijal Al-Hadis, Ilmu Tabaqat AlRuwah, Ilmu Tarikh Rijal Al-Hadis, dan Ilmu Jahri Wa Al-Ta'dil.

b. Ilmu hadi yang menkankan pada persolan matan hadis, seperti: Ilmu Gharib Al-Hadis, Ilmu Asbab Wurud Al-Hadis, Ilmu Tawarikh Al-Mutun, Ilmu Al-Nasikh Wa Al-Mansukh, Ilmu Talfiq Al- Hadis dan Ilmu Tashhif Wa Al-Tahrif.

c. Ilmu hadis yang menekankan pada persoalan sanad dan matan, seperti: Ilmu I'ilal Al Hadis, dan Ilmu AlFanni Al-Mubhamat

d. Manfaat dalam mempelajari cabangcabang ilmu hadis, antara lain: pertama; dapat memberikan pengetahuan tentanng cara menjaga As-sunah dan menghindari kesalahan dalam periwayatannya. Kedua; memberikan pengetahuan baru tantang cara mengetahui kualitas sebuah hadis, apakah hadis tersebut diterima dan ditolak, baik dari sudut sanad maupun matanya.

\section{DAFTAR PUSTAKA}

Amin, Kamaruddin. Menguji Kembali Keakuratan Metode Kritik Hadis. Cet. I; Jakarta selatan: PT Hikmah, 2009.
Ase, Ambo. Ilmu Hadis Pengantar Memahami Hadis Nabi Saw. Cet. I; Makassar: Alauddin Pers, 2010.

Itr, Nurudin. Ulum Al-Hadits 1 (Cet. II; Bandung: Remaja Rosdakarya, 1995.

Jayadi, M. Metodologi Kajian Hadist. Cet. I; Makassar: Alauddin Pers, 2012.

Manna' Al-Qaththan, Syaikh. Mabakhitsu Fii'Uluumul Hadits, terj. Mifdhol Abdurrahman, Pengantar Studi Ilmu Hadis. Cet. I; Jakarta Al-Kautsar, 2005.

Sabir Maidin, Muhammad. Ingkar Sunah Atau Hadis I Dalam Perspektif Historis. Cet. I; Makassar: Alauddin Pers, 2012.

Sugiyono, Metode Penelitian Pendidikan Pendekatan Kuantitatif, Kualitatif, dan R\&D. Cet. XIV; Bandung, 2012.

Soetari, Endang. Ilmu Hadis.Cet. II; Bandung; Amal Bakti Pers, 1997.

Suparta, Munzeir. Ilmu Hadis. Cet. VIII; Jakarta: PT Rajagrafindo Persada, 2013.

Shiddieq, M. Habsi Ash. Pokok-Pokok Ilmu Dirayah. Cet. VI; Jakarta: Bulan Bintang, 1994.

Zuhri. Hadits Nabi Telaah Historis dan Metodologis. Yogyakarta: PT Tiara Wacana Yogya, 2005. 